\title{
Towards integrated participation: involving seldom heard users of social care services
}

Louisa Hernandez, Paul Robson* and Alice Sampson, Centre for Institutional Studies, University of East London

*formerly Centre for Institutional Studies, University of East London.

Correspondence to: Alice Sampson. A.sampson@uel.ac.uk

Accepted by British Journal of Social Work, July 2008.

\section{Summary}

Using information from interviews with 41 service users and 32 staff from eight organisations a practice model is developed to show how those typically excluded from user participation be included into everyday participation to develop services and policies. The practice model outlines the processes necessary to promote and institutionally embed participation. The uncertainties and tensions which arise from these activities are also discussed. The value of the findings presented in this paper is that they provide information about how service user participation may be achieved.

Key words user participation, social care services, practice model. 


\section{Introduction}

The principle of involving users of social care services in the development of policies and services has been incorporated into legislation and government guidance. Requirements for the participation of service users are included in: 'Valuing People' White Paper for those with a learning disability (DoH, 2001), and for those with long term health problems (DoH, 2005), for example. Frameworks such as 'A Stronger Local Voice' aim to 'create capacity for an independent voice at a local level in commissioning health and care services, assessing the quality of services provided and in the regulation of the health and social care system'(DoH, 2006, p.7). How people decide, choose and control the social care services they require is further supported by the latest central government concordant 'Putting People First' (DoH, 2007).

Despite this framework, issues remain about how to involve groups of service users who have typically been marginalised or excluded from service user participation, described as 'seldom heard' users (Carr, 2004; Begum, 2005, 2006). Four seldom heard groups were identified by the Social Care Institute of Excellence (SCIE), the commissioners of the research presented in this paper; homeless people with addictions, people from black and minority ethnic communities, people with communication impairments, and those with dementia. We use findings from this small study to contribute to an improved understanding about how seldom heard groups and social care services can work together to establish inclusive involvement practices.

This paper is structured as follows: after different meanings given to participation are discussed, an account is given of the data collection and analysis that contributed to the development of a practice model. The research findings which informed the constituent 
elements of the practice model are then described. The main difficulties and tensions experienced when organisations participating in the research endeavoured to achieve everyday participation are highlighted to illustrate the problems they encountered. In the final section it is argued that the strength of the practice model is that it provides an explanation to policy-makers and practitioners about how everyday participation with 'seldom heard' service users can be achieved.

\section{Participation issues}

Studies have typically identified practices and contextual factors that facilitate participation including providing transport, using interpretation and translation services, allowing adequate time, culturally sensitive practices, and recognising users' complex and multiple needs (Byng et al., 2002; Cantley et al., 2005; Chahal and Ullah, 2004; Cook et al., 2003; Law et al., 2005; Begum, 2006).

Other studies have identified barriers that prevent integrated participation and perpetuate the marginalisation of seldom heard groups. Barriers include cost, different priorities between fund giving and recipient organisations, lack of information, inadequate staff expertise and lack of cultural knowledge, and racial prejudice ( $\mathrm{Yu}$, 2000; Evans and Banton, 2001; Harris and Bamford, 2001; Fountain and Howes, 2002; Vernon, 2002; Hussain et al., 2002; Parr et al., 2004). However these studies present limited information about how participation can be achieved (Moriarty et al., 2006). In this paper a practice model is presented that addresses this gap in our knowledge.

A multitude of terms related to participation have tended to confuse debates about the practice of participation. Terms include engagement, consultation, involvement, and representation. As a result there have been different approaches to conceptualising and 
making sense of its multi-dimensional nature. Some user-led organisations have focused on the distribution of power as a fundamental defining characteristic of relationships between service providers and service users (see Beresford and Croft, 2004; Carr, 2004; Cantley et al., 2005; Barnes and Mercer, 2006). The desired outcome of participation is a transfer of power from providers to users to enable users to participate at every level of decision-making, to be in control of the services they receive (Beresford and Croft, 2001), and, through user-led networking, to effectively campaign for more resources, improved policies, and better services (Branfield et al., 2006) and involvement in policy-making (Cook, 2002). This requires significant financial resources and a considerable number of services users with the capacity, time, skills and interest to participate in all of an organisation's decision making situations (Campbell et al, 2007). This approach also assumes a participation hierarchy, giving us the now familiar ladders metaphor (Arnstein, 1969; Hart, 1997) which gives higher status to participation in policy making and resource allocation than participation in everyday activities.

Efforts have been made to move away from a hierarchical structure to a whole-systems approach (Wright et al., 2006) which recognises that different aspects of an organisation - culture, structure, practice and review need to be addressed simultaneously and welded together like interlocking jig-saw pieces (Leonard Cheshire, 2005). In this approach no particular type of participation activity is accorded a higher status over another.

In our study we found that service users preferred a nonhierarchical approach and our findings develop this perspective further by focusing on users' priorities in service design (Robson et al., 2008; Bowes, 2006). Research with black disabled people identified the importance of meeting people's practical needs before engaging them in research and development projects (Singh, 2005). Research on 
consulting people with dementia found that 'opportunities for the person to express themselves, rather than adhering to a specific procedure or technique' (Allan, 2001, p. 2) and integrating involvement into care routines were favoured by users (Allan 2001, 2002). This integrated approach stands in contrast to situations where participatory activities are 'added-on' to the delivering of social and caring services. Add- on suggests participation is an 'activity' that can just as easily be removed as supplied. By integrating involvement into the every-day it is perhaps much harder to justify its removal or reduction.

\section{The study}

The purpose of the study was to develop a practice model to explain how social care organisations can work towards establishing integrated everyday participation for seldom heard service users. To address the problem of generalising from the findings of our small study we adopted a theory-driven approach to explain how policies and practices affect user involvement. This approach is based on the belief that generalisations can be made by developing a causative theory - a practice model (Chen and Rossi, 1992; Grange, 1998).

\section{Sampling}

To keep within our research budget we selected two organisations from each user group identified by SCIE. The primary criteria for selecting organisations were that each organisation had experience involving service users. This enabled research participants to draw on personal experience, rather than attempt to talk about abstract or hypothetical situations. Organisations were also selected where staff and service users were willing to participate in the research. At least two similar types of organisations were selected: day centres or hostels which were voluntary sector-led, for example, to give us the opportunity to more meaningfully compare and contrast the ethos and 
working practices of similar organisations. We sampled to maximise the variation in approaches to user involvement across the sample as a whole (eight organisations), and purposively selected organisations located in different regions and in urban and rural areas across Britain, in order to maximise the contextual variations in which policies and procedures were put into practice. This purposeful sampling enabled the research to draw on practices in diverse locations and to identify a range of mechanisms which were actively contributing to the promotion of user involvement across a variety of contexts and situations.

The two voluntary organisations for people with dementia were both day centres; one was located in a homely Victorian house in a rural setting in southern England and the other in a purpose built open- plan converted church in a Scottish city. Both organisations provided support services, information and advice, and ran activities such as domino tournaments and computer clubs; one had a long tradition of user involvement and the other had less well-integrated practices. The communication impairment organisations both worked with groups throughout their region, one in the south east and the other in the south west of England. A local authority sensory disability team worked with deaf and blind people to enable them to take part in services development and a voluntary organisation for those with aphasia involved users in policy development and service delivery.

Two residential hostels for homeless young people with drug addiction problems were selected. Both were run by voluntary organisations, one being in central London and the other in a northern city. The hostels provided educational opportunities, organised activities and had drug treatment programmes. Both were committed to involving users but in one hostel staff tried to control and manage the process whilst, in the other, the users' views were given privileged status. One of the black and minority ethnic organisations was a 
young people's resource centre on the south coast of England where young people were able to drop-in and receive counselling, attend group activities, and receive information and advice. The building was run- down and chaotic but warm and informal and encouraged young people to make decisions about services and policies. The other black and minority ethnic organisation was also voluntary sector managed, and provided day time activities for older people, offered transport toand-from the centre. Users were called members, which gave them participation rights and they were encouraged by staff to campaign for improvements in services.

With respect to sampling interviewees, a researcher visited an organisation on pre-arranged days, which were different days of the week and times of the day. Those who were attending when the researcher visited, and were willing to participate in the research, were interviewed. This approach enabled a range of experiences within an organisation to be gathered and, at the same time, was pragmatic and inclusive. A senior manager from each organisation was interviewed, as well as frontline staff on duty.

\section{Data collection}

A review of the literature was conducted to identify key issues faced by the types of seldom heard groups participating in the study, and to identify any gaps in our understanding about how to facilitate participation amongst these groups. Using this knowledge, interview schedules were developed to facilitate a systematic approach to finding out how participation operates, how users like participation to operate, the decisions they were involved in, and to find out which processes bring about inclusive participation.

Our approach to data collection was flexible and inclusive. We gathered background information on organisations and sometimes 
made preliminary visits to discuss with staff and users how they would prefer to participate in the research. We adapted interview schedules for each organisation and interviewees were shown the schedule in advance of the interview to give them time to reflect on the questions and to add any information they felt was relevant. To be inclusive, researchers made every effort to accommodate users' needs and circumstances. Arrangements were made as needed to have language interpreters, signers, and support workers. Before interviews started the researcher clarified with the interviewee that they understood what the research was about and interviewees signed consent forms. Researchers made it clear to interviewees that they did not have to answer all the questions and that they could stop the interview at any time. Interviewees were asked if they preferred to talk to the researcher alone or to be part of a group. We found that people with communication impairments and people with dementia often preferred small group interviews, with three or four people they already knew. The group support enhanced communication and, in turn, increased the amount of information disclosed to the researcher. For example, one person had very little speech and the group setting gave her the opportunity to indicate agreement and disagreement with her colleagues' contributions (see Hubbard et al., 2002).

The relaxed and conversational style of interviewing allowed interviewees to feel comfortable and gave them time to respond at their own pace. All the fieldwork researchers had experience of interviewing people with disabilities and people with complex social problems. The researchers drew on their experiences to put interviewees at ease and to encourage them to communicate. Some interviewees did not wish the interviews to be taped and, where this occurred, the researcher took notes during the interview and further notes immediately after the interview. 
We conducted the fieldwork between October 2006 and March 2007, and, on average, the interviews lasted an hour. A summary description of the selected organisations and the number of interviews completed is shown in Table 1 below.

Table 1 Projects and number of interviews

\begin{tabular}{|c|c|c|c|c|}
\hline $\begin{array}{l}\text { Ref. } \\
\text { No.* }\end{array}$ & Group & Description & $\begin{array}{l}\text { Number } \\
\text { interviel }\end{array}$ & \\
\hline & & & $\begin{array}{l}\text { Service } \\
\text { users }\end{array}$ & Staff \\
\hline 1 & Dementia & $\begin{array}{l}\text { Day care service in SE } \\
\text { England run by national } \\
\text { voluntary organisation. }\end{array}$ & 5 & 2 \\
\hline 2 & Dementia & $\begin{array}{l}\text { Day and evening centre in } \\
\text { Scottish town run by } \\
\text { voluntary organisation. }\end{array}$ & 3 & 3 \\
\hline 3 & $\begin{array}{l}\text { Communication } \\
\text { impairment }\end{array}$ & $\begin{array}{l}\text { Activities organised in } \\
\text { many venues in rural area } \\
\text { in SE England by local } \\
\text { authority team }\end{array}$ & 2 & $\begin{array}{l}5 \text { (1 with } \\
\text { sensory } \\
\text { disability) }\end{array}$ \\
\hline 4 & $\begin{array}{l}\text { Communication } \\
\text { impairment }\end{array}$ & $\begin{array}{l}\text { Specialist voluntary } \\
\text { organisation run project } \\
\text { for those with aphasia in } \\
\text { south west England }\end{array}$ & 7 & 3 \\
\hline 5 & $\begin{array}{l}\text { Homeless and } \\
\text { addictions }\end{array}$ & $\begin{array}{l}\text { Hostel in central London } \\
\text { run by a voluntary } \\
\text { organisation }\end{array}$ & 5 & 8 \\
\hline 6 & $\begin{array}{l}\text { Homeless and } \\
\text { addictions }\end{array}$ & $\begin{array}{l}\text { A residential hostel and } \\
\text { day resource centre in } \\
\text { Northern town and run by } \\
\text { voluntary organisation }\end{array}$ & 8 & 7 \\
\hline 7 & $\begin{array}{l}\text { Black and } \\
\text { minority ethnic }\end{array}$ & $\begin{array}{l}\text { A voluntary sector resource } \\
\text { centre for young people in } \\
\text { a coastal town in Southern } \\
\text { England. }\end{array}$ & 6 & 2 \\
\hline 8 & $\begin{array}{l}\text { Black and ethnic } \\
\text { minority }\end{array}$ & $\begin{array}{l}\text { Day centre for older people } \\
\text { in an inner city London } \\
\text { Borough, run by a } \\
\text { voluntary organisation. }\end{array}$ & 5 & 2 \\
\hline & TOTAL & & 41 & 32 \\
\hline
\end{tabular}

* 'ref. no.' is the reference given to each organisation which is then used in brackets after a quotation is used from a service users or member of staff to identify which organisation the comment has come from. 
Of those interviewed 39 were women and 34 were men. Over three quarters were White (78\%), and the remaining $22 \%$ described themselves as Black African (4) mixed race including black and white and African and Spanish Arabic (4), Greek (3), Pakistani (2) and one Chinese and one Indian. Information on the ethnicity of one interviewee was not collected. The age range of just over a quarter of the interviewees was also not collected $(27 \%$ but where data were available, the majority were 31 - 45 years (40\%). An equal proportion were aged $16-30$ years (30\%) and 46 years and over (30\%) with four interviewees aged over 75 years.

\section{Data analysis}

The analysis of the data was informed by our research remit which was the production of a practice model to inform organisations about how they can develop participation with seldom heard service users. We read and re-read all the interview transcripts and notes and manually identified factors, and relationships between factors, which facilitated and explained participation. One researcher then collated the information and presented a practice model to the rest of the research team. We reviewed the constituents of the model, re- read interviews to increase our confidence that key explanatory factors had not been omitted and to reassure ourselves that the identified factors arose from the data, rather than from our own values (Doucet and Mauthner, 2003).

The analysis process was sequential; firstly we identified from the data the type of participation preferred by service users. The preferences of the service users were consistent across organisations; namely, to 'get involved' in everyday work, services, activities, relationships and events. Developing everyday participation which may or may not include campaigning and networking with other users across organisations emerged as a common theme in interviews with 
staff. Having identified working towards everyday participation as the goal for the practice model, we then read the interviews again to identify the relevance and significance of themes and mechanisms that facilitated participation.

Our analysis of the data was theory-driven; we adopted a hypotheses- testing approach to generate explanatory information to enable general practice principles to be extracted from the data. It is these practice principles or generative causal mechanisms which are transferable and form the basis for developing a practice model which can be used in different contexts and by different organisations (Sayer, 1992; Pawson and Tilley, 1997, p. 120-3; Parmar and Sampson, 2007). Where the data fit one particular explanation better than other explanations, this hypothesis was considered the most plausible explanation (Popper, 1968, 1969). As a result of this second stage of the data analysis the best hypothesis which fit the data was: if seldom heard service users are to be included in everyday participation then appropriate practices and policies are those which enable two way communication between staff and service users and enable service users to support each other.

The third stage of the analysis was to identify how integrated everyday participation can be achieved. Factors were identified which explained how service providers and service users can work together (the sentences in italics in Figure 1, which is introduced shortly). They may be described as the practices that create an organisational ethos that recognises the value of participation and provides the opportunity for participation to be nurtured. Factors which enable service providers and users to achieve everyday participation are beliefs and values which embrace participation (the sentences in boxes in Figure 1). The factors which are the response to social interactions or activities explain how changes in practices occur (the sentences in bold type in Figure 1). The links between the factors (either one way or two way arrows in Figure 1) arise from the hypothesis building approach to the data analysis which describes a process of change; for 
example, if users feel confident to get involved and try different activities then they are able to contribute and to help other service users and, in turn, this gives them the confidence to discuss/criticise services and service providers (see Figure 1).

In order to improve our understandings of how the model may work in practice we identified from the interviews a plethora of uncertainties and tensions which drew attention to the difficulties of bringing about everyday participation and highlighted factors that required negotiation in order to achieve a positive outcome. These findings are summarised in table 2 which is discussed later in the article.

Integral to the data analysis was inviting criticisms of the model. A provisional practice model and a summary of the tensions were presented for discussion to members of the research advisory group, with the organisations who had participated in the research, and at two workshops at a Social Care Institute for Excellence national conference. This consultation process gave us the opportunity to refine the model. We added more two- way arrows to depict a strong inter-relationship between staff sensitivity to service users' circumstances and organisational support of the inclusion of seldom heard users, for example. The refined model is presented in this paper.

\section{Limitations of the research}

This study is about how to engage with seldom heard service users and does not include the separate issue of how to engage with those who might benefit from services (for a discussion on these issues see Ahmed et al., undated; Warburton, 2006). Nor does the research address the problem of how to motivate reluctant organisations to embrace an ethos of promoting user participation for the development of its services and policies. Such an ethos embodies institutional 
values that foster a growth in user involvement (Law et al., 2005; HASCAS, 2005).

The research was also designed to find out about the process of involvement rather than to assess measuring outcomes. We recognise that the process of involvement has outcomes and these are incorporated into the practice model described in figure 1 but we did not collect data on how to measure them which is itself a challenging task (Doel et al., 2007).

We recognise that the search for possible causal mechanisms is difficult and full of uncertainties. Many hypotheses can be explored and different types of data collected. Causal explanations might not involve identifying common characteristics shared across organisations (Sayer, 1992). Time limited research grants and limited funding allocated to research studies curtails the search for alternative hypotheses (Weiss, 1997a), and raises the possibility that researchers may fail to identify key causal mechanisms. During the research we were aware of these possibilities and this knowledge led us to continuously reflect on our data, question our data analysis, and discuss the inferences we were making to 'check' that our judgements were credible (see Campbell, 1979; Cordray, 1986 for a discussion on how making judgements about causal inferences can be problematic). Finally, since the practice model is itself a hypothesis, it requires further testing and improvement.

\section{Features of the model derived from the findings}

The following describes the model and shows how it arises from the research findings: 
Figure $1 \mathrm{~A}$ practice model to enable everyday participation

Seldom heard service users are often excluded from user participation

Enabling two way communication between staff and service users and enabling service users to support each other

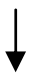

Staff sensitivity to service users' circumstances, and access needs which offer reassurance to service users
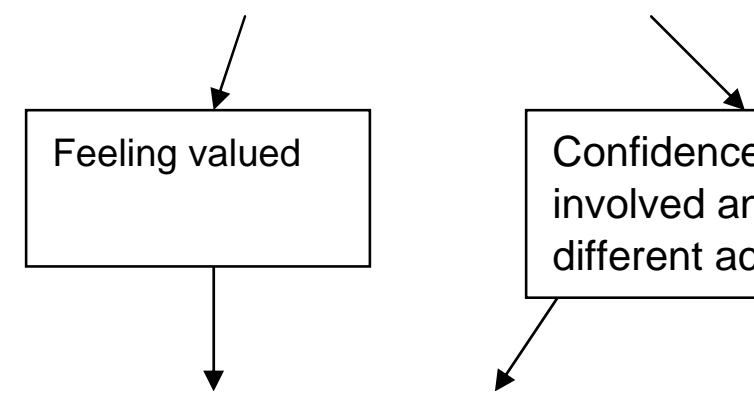

Ability to contribute and to help other service users

Confidence to discuss/criticise services and service providers

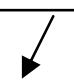

Staff respond to feedback including criticisms
Organisational support for

the inclusion of seldom heard users

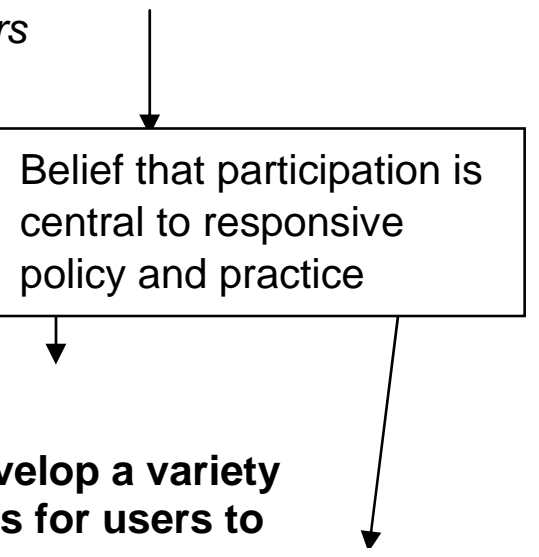

Capacity to develop a variety of opportunities for users to get involved

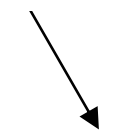

Strategies for overcoming constraints Climate where everyone expects, promotes and supports participation

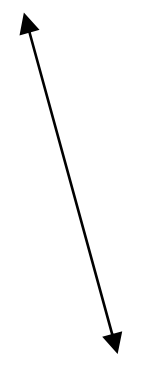

Joint problem-solving and improvements to policies \& practices

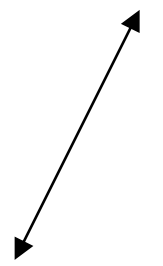

INTEGRATED EVERYDAY PARTICIPATION

Seldom heard service users are included. 
How service providers and service users work together (sentences in italics)

The model shows how three key practices inform how service providers and service users can work together. These are the practical conditions which are necessary for everyday participation to occur.

Each practice is discussed in turn and information from interviews used to illustrate how working together can be fostered.

Staff sensitivity to users' circumstances and access needs

Service users spoke about issues that were personal to them that affected whether, when, and how they got involved. These included such things as their own capacity in terms of energy or motivation (particularly relevant in the case of conditions such as depression or addictions), cynicism about whether services could help or genuinely wanted their views, and the fear that criticism of services would affect current or future access to services or endanger financial support for services (for similar findings see Bott and Rust, 1997). Users explained that they sought out staff who offered particular types of support. The following explanations were typical comments from users:

They don't say 'we don't have time'. (7)

We've got (staff member) - she's so calm and kind. She doesn't laugh at me if I do something wrong. (1)

Users from many of the case studies described how they were not under pressure:

we can take it slowly'... 'You're not worried that you're not doing or saying the right thing. (4) 
Staff recognised the importance of creating a safe place describing how 'young people have come from a culture and environment where it is either not acceptable to voice an opinion or not safe to' (7). Staff talked of not rushing, and creating space and time 'to enable people to go at their own pace' (3).

We found staff sensitivity to service users' circumstances and access needs offered reassurance to service users. Staff described the multiple and complex issues users faced and the pressures they experienced, and how it was a matter of 'knowing people very well' (1). A user with dementia appreciated this approach:

They (the staff) write things down when we are finished. A few words. Key issues. They send this paper to your home so that you know what happened. A memory. (3)

Staff awareness that users' circumstances changed quickly led to a flexible approach. Staff described how they should not be 'too fixed in (their) thinking' (2) and emphasised that users should be 'given choice to take part or not depending how they feel' (8).

Responding to circumstances which left users feeling isolated and led them to withdraw socially and reluctant to participate was a recurring theme in the research. Difficulties in communicating were isolating and we found that effective communication with people with dementia directly led to their involvement in activities. Similar to other research we found that staff needed support and encouragement to improve communication with people with dementia (Allan, 2001), signifying the importance of staff training for fostering a culture of participation. 
Findings from interviews revealed staff had different perspectives on their roles and responsibilities with respect to fostering participation and, as a consequence, different types of institutional support were available. Some organisations thought that it was their responsibility to remove barriers to participation. A member of staff explained:

We provide the necessary practical support; travel money, vouchers, lunch.... (5)

In several organisations staff proactively engaged in advocating on behalf of service users. A member of staff gave an example:

One man was refused by his local church choir. We helped him to lobby the church. Barriers are a lack of awareness, by others, about supporting people with dementia. (1)

Staff in another organisation believed in giving participants financial rewards:

We are asking people to give their time for something that we want (their views). This should be respected. Our county council is producing a payment policy soon. (3)

Where organisations redefined their role as 'provider' some practices blurred the traditional boundaries between provider and user, and everyday participation was more deeply embedded institutionally. In one organisation providing services for those with dementia, a service user was able to join in with staff activities such as preparing lunch, rather than remain in a 'user' role. In this way staff found ways of accommodating service users' aspirations and expectations. 
The research findings revealed that many activities were taking place that encouraged feedback. These included: youth forums, policy groups, one-to- one sessions, complaints boxes, making time for regular informal conversations, using drama, and interpreters. For a group of participants with aphasia capturing non-verbal communication, and staff double-checking that they had correctly interpreted what a person had wanted to convey, was integral to the feedback process.

Our research showed that there was a mixture of success and failure regarding responding to complaints and that some staff lacked an understanding about how to respond to negative feedback. Those organisations which valued and prioritised participation explained their complaints policy at staff inductions, and were clear about how staff were to respond to complaints from service users. Users' experiences illustrated the importance of induction programmes for all staff. Examples were given of situations where a new staff member lacked an understanding of how upsetting certain actions were. One service user commented:

she didn't realise that we take things literally. I think she was told. (1)

Where clear rules were adhered to this created the best conditions for change, and was appreciated by service users. A user commented:

If three young people complain on the same day then change has to happen. It's fantastic. (7)

Where there was an organisational ethos that valued participation complaints and criticisms were understood as integral to a service 
rather than an activity that had to be endured or suppressed. In one organisation two members of staff explained why and how they encouraged complaints:

I like to ask their opinions. The day centre is for them really it's not for me to put my rules and regulations and beliefs into them. (8)

They have got a complaints form as well. If they are not happy it is their right to complain. That's what I keep telling them. 'The form is there, don't be shy, don't think that I am going to tell you off'. (8)

\section{Factors to achieve everyday participation (the information in boxes)}

Five factors were identified in the research that facilitated everyday participation (see figure 1). Firstly the factors important to the users are discussed and secondly the two organisational factors important to the staff.

Feeling valued, confidence to get involved, and confidence to discuss/critise services and providers

An integrated, everyday approach to participation emerged from the efforts of staff to build strong relationships with service users which developed trust, mutual understanding and respect. The interviews with service users found that they valued staff who were inclusive, positive, optimistic, and non- judgemental. A service user commented:

no- one outside the family knows I have Alzheimers' Disease... In most other places I was becoming more and more timid....The staff are nice. They look after us well. Not in the 
sense of looking down on us. It's so easy for people to think you're inferior. (1)

In common with other studies we found that where service users were respected they were more likely to actively engage with staff and consider participating. Bamford and Bruce (2000) asked people with dementia about the outcomes they wanted from services. They identified autonomy, having a say, feeling valued and respected, and being treated as a 'normal' person. A group of older Chinese people valued being respected and wanted their involvement activities to be recognised and appreciated (Chau, 2007). Similar conclusions are drawn from our research. Young people described how they were motivated to participate by the hostel manager who "had a belief in people and an optimism about them' (5). Where there was respect, relationships between service providers and users were reciprocal and users felt valued and able to contribute. One service user explained that the staff:

understand me. It makes me speak up. They ask people what they would like to do... I feel they can take my ideas. (7)

People with communication impairments felt valued as a result of being trained to become communication trainers. They liked being involved in something that 'helps them and it helps us' (4). During the training they had time to talk and to laugh and because there was adequate time they knew that 'when you make mistakes it doesn't matter' (4). Feeling that it did not matter if they made mistakes, and being encouraged to recognise that learning was a process of 'trial and error' explained why users 'experimented' with participation and why they felt able to continue to participate.

Integral to the practice of everyday participation is a culture where users feel able to discuss, and if necessary criticise, services and 
providers. It is through this dialogue that the relevance and quality of services and service delivery can be refined and improved. Yet we found that many users were reluctant to enter into these types of conversations through a fear of loosing the service. Positive attitudes of the staff and organisational encouragement gave users confidence to discuss services.

Belief that participation is central to responsive policy and practice, and a climate where everyone expects, promotes and supports participation

In organisations where participation was positively promoted we found that user involvement was embedded in policies and procedures. Improvements that occurred through their involvement included running different levels of language classes, the provision of better quality services, and having 'proper knives and forks in the canteen' (6). Staff commented on some positive consequences of successfully promoting an ethos of participation:

There has been a noticeable power shift. A lot of barriers have been broken down between staff and service users. (6)

It seems too easy to say we just maintain involvement. It's quite seamless. I don't know where the service user ends and the staff begins. We have low staff turnover. For staff it's the 'in thing'. You've got to be 'in it' while you're doing it.... Tune in and go with it. You need to go to where people with dementia are. Sometimes you don't bring all of yourself back. (2) 


\section{Responses to the social interaction or activity (sentences in bold)}

In order to understand decision-making we used Weiss's concept of 'mechanisms of change'. Weiss stated that: 'The mechanism of change is not the program activities per se but the response that the activities generate' (Weiss, 1997b, p. 46). Responses may include improved self- confidence or feeling supported.

\section{Ability to contribute and to help other service users}

The process of change from feeling more confident and feeling valued to actually participating was not an automatic or linear progression. Service users found it difficult to articulate the transformation of beliefs and feelings into actions and this may be due to deep-seated values held unquestioningly by interviewees. Users were, however, able to reflect upon their actions. Many reported a satisfaction and a 'sense of purpose' when they did things for themselves and helped others. One participant described how he would 'encourage other residents who were not so confident who saw me getting involved' (5). A user who observed this behaviour commented on its positive consequence for improving participation: 'There is a tendency for one to motivate others. A sort of gluey effect' (5). Where this occurred we found users helping to run music activities and computer courses.

Feeling able to contribute can lead to action. An interviewee commented:

The staff recruitment has been very satisfying, and the peer quality auditing, because I can make a valued contribution. (5)

Where users worked together and acted as a group, they were encouraged to communicate and to take actions. A user with asphasia described the value of this process: 
We work as a group. We can talk through other people. We help each other. (3)

Capacity to develop a variety of opportunities for users to get involved

We found that where everyday participation was encouraged organisations provided many opportunities for users to get involved. Being able to choose from a range of activities facilitated the process of involvement but only when staff did not relentlessly 'push' users into participating. Service users praised the balance between encouragement to get involved and trying new things and the option to slow down or withdraw. The following comments by one member of staff encapsulated this position:

It is an arrogance to plan someone's day for them. We go with the flow, people themselves initiate. Staff would suggest but not herd. Members may choose to do nothing. (1)

Respecting decisions made by users not to participate and adopting a non-judgemental approach had the effect of retaining enthusiasm for participation. A non-judgemental approach with a 'can- do' or 'havea-go' attitude that was not tied to a particular outcome provided a context that encouraged users to 'experiment' participating in a range of activities. Underpinning this approach was an ethos that did not label users as 'failures' if they decided to opt out. Instead they were encouraged to try participating in a different way by attending a meeting to discuss a procedure, or by assisting with a dancing group.

A consequence of developing a range of opportunities for users was increased staff motivation which, in turn, improved the quality of services they provided. A user commented on the benefits of having a 
choice of activities to participate in, and how having a choice contributed to continued participation:

It's good for you. It's got to be so it makes you want to come back. There's choice. They're (staff) never weary. They share your interests and ideas. (2)

\section{Strategies for overcoming constraints}

The findings from our small study are limited and other larger studies have identified additional creative solutions to overcome barriers to participation (for example, Byng et al., 2002; Cook et al., 2003; Parr, 2004). In our study barriers ranged from a lack of belief by staff that users with conditions such as dementia and asphasia were able to contribute, to insufficient thinking time allowed at meetings for some people with impairments, and harassment on public transport.

In this section we are, however, concerned with understanding how difficulties are overcome. Two recurring themes occurred in our research. Firstly, it appeared that getting the practical side right flowed from staff commitment to participation, and that starting with practical problem solving provided a platform for participation. Staff in one organisation described how they would adapt and be flexible in supporting participation:

People are supported to do absolutely anything and everything

- go to the bank, shopping, attend appointments, maintain life- skills, anything. (2)

A second strategy to overcome constraints was a theme around the ability of staff and users to listen and a willingness to communicate meaningfully. One staff member talked about the use of language and the importance of how to communicate: 
in the youth forum there are group agreements. But if we start talking about terms of reference etc the young people say it's boring and 'can't they just get on with it, it's a waste of time. (7)

Joint problem-solving and improvements to policies \& practices

In organisations where service users felt confident to make complaints and discuss the services, the culture of staff- user joint problemsolving enhanced the opportunities for everyday participation. We found that users were typically very satisfied with this approach. A day centre ran groups for older people from Greek, Afro-Caribbean and Asian communities. These groups had lunch together, participated in activities, and received advice and information about other services. Some members of the group raised issues about the standards of home care with staff who supported them to complain to social services. Similarly, problems with the council's transport service were resolved by group members writing letters asking for change.

A member of staff reflected on the positive impact of this successful action. An improved transport service enabled more people to use the centre and for the users it provided incentives for further joint problem- solving. The staff member commented:

so this was just an example that showed them that they had the power and that your opinions count. (8)

In another organisation a small group of people with dementia met once a week as part of a computer project. One issue the group discussed concerned a National Institute for Clinical Excellence decision about dementia treatment. With the support of staff the group decided to take part in a demonstration in central London. 


\section{Working with uncertainty and tensions}

During our research it became apparent that participation was not a straight forward solution to a problem of inadequate or inappropriate services and policies. Rather we found that the multi-dimensional nature of participation, and the expectation that it can solve many problems, creates real dilemmas and tensions for practitioners. Our research findings revealed a multitude of tensions related to putting everyday participation into practice. Staff and service users had to navigate their way through a number of uncertainties to ensure that people could get involved and achieve some positive outcomes.

Table 2 below summarises some of the tensions. The double arrows represent the space between the tensions where judgements and decisions are made about how to proceed. For staff this often involved balancing the high expectations and demands made by commissioners of services and a strong desire not to set up users to 'fail'. 
Table 2 Tensions and pressures arising from promoting participation

\begin{tabular}{|c|c|c|}
\hline $\begin{array}{l}\text { the need to have a clear } \\
\text { purpose for any service, } \\
\text { group or event }\end{array}$ & $\longleftrightarrow$ & $\begin{array}{l}\text { a variety of choices about } \\
\text { what to get involved in }\end{array}$ \\
\hline $\begin{array}{l}\text { clear messages about what } \\
\text { was expected of service users }\end{array}$ & $\longleftrightarrow$ & $\begin{array}{l}\text { flexibility and adaptability } \\
\text { of approach towards } \\
\text { involving users }\end{array}$ \\
\hline $\begin{array}{l}\text { meeting participation outputs } \\
\text { set by external agencies e.g. } \\
\text { number of people finishing a } \\
\text { course }\end{array}$ & $\longleftrightarrow$ & $\begin{array}{l}\text { respecting individual } \\
\text { service user circumstances, } \\
\text { priorities, and needs }\end{array}$ \\
\hline $\begin{array}{l}\text { meeting management } \\
\text { demands for consultation on } \\
\text { policy or practice }\end{array}$ & $\longleftrightarrow$ & $\begin{array}{l}\text { focusing on the process of } \\
\text { involving people }\end{array}$ \\
\hline $\begin{array}{l}\text { encouraging users to get } \\
\text { involved and having high } \\
\text { expectations about what they } \\
\text { can achieve }\end{array}$ & $\longleftrightarrow$ & 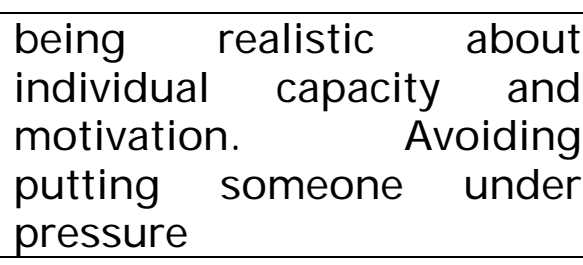 \\
\hline 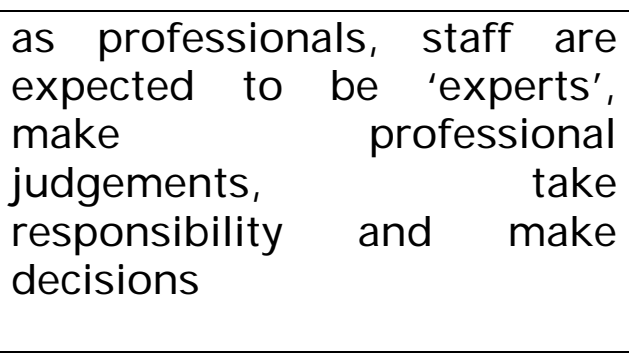 & $\longleftrightarrow$ & $\begin{array}{l}\text { the ethos of user } \\
\text { participation requires staff } \\
\text { to incorporate the expertise } \\
\text { and experience of service } \\
\text { users and to share } \\
\text { responsibility and decision } \\
\text { making }\end{array}$ \\
\hline $\begin{array}{l}\text { participation as an activity } \\
\text { allocated to specific staff }\end{array}$ & $\longleftrightarrow$ & $\begin{array}{l}\text { participation as part of } \\
\text { everyone's work }\end{array}$ \\
\hline
\end{tabular}

Where staff valued participation as an essential organisational activity, even a 'right' of service users, they tended to be more creative in their practices and facilitate a 'safe space' for everyday participation. This required insulation from 'tick box' approaches to user involvement and unsupportive organisational environments. This tension was increased when a service relied on a number of funding strands, each 
of which required different reports to describe the outcomes of the sections of work they were paying for. One staff member described how seldom-heard participants were constantly having to fill in forms and were losing 'the magic' of participation (7).

Two key enabling factors identified by many staff and users were time and money. The process for developing strong relationships based on trust, respect and mutual understanding required a considerable amount of time. This implied that time limited projects, services and consultations (including this research project) will always have limited scope for engaging seldom heard groups. Funds were needed to ensure practical access to information, and that participation in meetings and services could happen.

Some staff were employed as specialists to support, for example, skills development, lesbian and gay young people, and those with communications impairments. While this provided new knowledge, there was a danger that other staff members might not develop their own knowledge and confidence to support all service users. In this case, it could be said that specialist staff also became 'add-ons', creating silos of good knowledge that could be lost if unshared and/ or funding was time limited.

\section{Conclusion}

Previous studies about user participation have given little attention to how participation can be achieved (Moriarty et al., 2006). In this paper we have addressed this issue by using findings from a small sample of seldom heard users and staff of social care services to construct a practice model which shows how everyday participation can be facilitated. Using a hypothesis generating approach to analyse interview data, the model explains how staff and service uses can work together to support each other in order to achieve integrated everyday 
participation. The model shows three types of inter-locking factors which explain how participation occurs; practical factors that contribute to a positive organisational ethos, practices which foster a set of appropriate values and beliefs, and factors which are reactions to practices and activities which explain how changes occur. The study also highlights the tensions and uncertainties that arise, and how involving seldom heard service users is a complex process that requires skilful negotiations and strategies by service users and staff.

By finding out how participation can be achieved and by identifying the tensions that require negotiation, this paper provides policy-makers and practitioners with valuable information which enables legislative frameworks and government guidance to become a practical reality for service users. The practice model presented in this paper demonstrates the value of practitioners focusing on how the problem of involving seldom heard service users can be addressed and practices which bring about change, rather than concentrating on what can be done. 


\section{References}

Ahmed, S., Hussain, M. and Vournas, G. (undated) Consultation with 'Hidden' and Hard-To-Reach Groups: Methods, Techniques and Research Practice, Trescom Research \& Consultancy Limited, available online at www.laria.gov.uk/content/features/68/feat1.htm (accessed 22 September 2006).

Allan, K. (2001) Communication and Consultation, Exploring Ways for Staff to Involve People with Dementia in Developing Services, Bristol, Policy Press.

Allan, K. (2002) 'Focusing reflecting and exploring how to communicate effectively', Journal of Dementia Care, 10 (5), pp. 16 27.

Arnstein, S. (1969) 'A ladder of citizen participation in the USA', Journal of the American Institute of Planners, 35 (4), pp. 214- 224.

Barnes, C. and Mercer, G. (2006) Independent Futures, Bristol, Policy Press.

Bamford, C. and Bruce, E. (2000) 'Defining the outcomes of community care: the perspectives of older people with dementia and their carers', Ageing \& Society, 20, pp. $543-570$.

Branfield, F., Beresford, P., Andrews, E.J., Chambers, P., Staddon, P., Wise, G. and Williams- Findlay, B. (2006) Making User Involvement Work: Supporting Service User Networking and Knowledge, Joseph Rowntree Foundation Findings, November, York, Joseph Rowntree Foundation. 
Begum N. (2005) 'I'm not asking to live like the Queen.' The Vision of Service Users (or Potential Service Users) and Carers who are Seldom Heard on the Future of Social Care for Adults in England, unpublished, London, Social Care Institute for Excellence.

Begum N. (2006) Doing it for themselves: Participation and Black and Minority Ethnic Service Users, Participation Report 14, Social Care Institute for Excellence, available online at www.scie.org.uk/publications/reports/report14.pdf (accessed 22 September 2006).

Beresford, P. and Croft, S. (2001) 'Service users' knowledges and the social construction of social work', Journal of Social Work, 1 (3), pp. 295- 316.

Beresford, P. and Croft, S. (2004) 'Service users and practitioners reunited: The key component for social work reform', British Journal of Social Work, 34, pp. 53-68.

Bott, S. and Rust, A. (1997) 'Involving physically disabled users in service planning and delivery: Shropshire as a case study based on two national projects', Research Policy and Planning, 15 (2), pp. 38- 42.

Bowes A. (2006) 'Mainstreaming equality: implications of the provision of support at home for majority and minority ethnic older people', Disability and Society, 40 (7), pp. 739-757. 
Byng, S., Cairns, D. and Duchans, J. (2002) 'Values in practice and practising values', Journal of Communication Disorders, 35, pp. 89 106.

Campbell, D. (1979) 'Assessing the impact of planned social change', Evaluation and Programme Planning, 2, pp. 67-90.

Campbell S., Maynard, A. and Winchcombe, M. (2007) Mapping the Capacity and Potential for User-led Organisations (ULO) in England, Department of Health, available online at www.dh.gov.uk/en/Publicationsandstatistics/Publications/Publications PolicyAndGuidance/DH_078538 (accessed 30 September 2007).

Cantley, C., Woodhouse J. and Smith M. (2005) Listen to Us: Involving People with Dementia in Planning and Developing Services, Dementia North/ Northumbria University, unpublished.

Carr, S. (2004) Has Service User Participation Made a Difference to Social Care Services?, Position paper No. 3, Social Care Institute for Excellence, Bristol, Policy Press.

Chahal, K. and Ullah, A. (2004) Experiencing Ethnicity: Discrimination and Service Provision, Joseph Rowntree Foundation Findings, no. 914, available online at www.jrf.org.uk/KNOWLEDE/ findings/foundations/pdf/914.pdf (accessed 22 September 2006).

Chau, R. (2007) The Involvement of Chinese Older People in Policy and Practice, Joseph Rowntree Foundation, York, York Publishing Services Ltd. 
Chen, H. and Rossi, P. (1992) 'Introduction: integrating theory into evaluation practice', in Chen, H. and Rossi, P. (eds), Using Theory to Improve Program and Policy Evaluations, New York, Greenwood Press.

Cook, D. (2002) 'Consultation, for a change? Engaging users and communities in the policy process', Social Policy \& Administration, 36 (5), pp. $516-531$.

Cook J., Maltby, T. and Warren, L. (2003) Older Women's Lives and Voices: Participation and Policy in Sheffield, ESRC Growing Older Programme Research Findings 21, available online at www.growingolder.group.shef.ac.uk/Go_Findings_21.pdf (accessed 22 September 2006).

Cordray, D. (1986) 'Quasi-experimental analysis: a mixture of methods and judgment', in Troachim, W. (ed), Advances in QuasiExperimental Design and Analysis, London, Jossey- Bass Inc.

Department of Health (2001) Valuing People: A New Strategy for Learning Disability for the 21 st Century, A White Paper, available online at www.dh.gov.uk/en/Publicationsandstatistics/Publications/Publications PolicyAndGuidance/ DH_4009153 (accessed 30 September 2007).

Department of Health (2005) Supporting People with Long Term Conditions: An NHS and Social Care Model to Support Local Innovation, available online at www.dh.gov.uk/en/Publicationsandstatistics/Publications/Publications PolicyAndGuidance/ DH_4100252 (accessed 30 September 2007). 
Department of Health (2006) A Stronger Local Voice: A Framework for Creating a Stronger Local Voice in the Development of Health and Social Care Services, available online at www.dh.gov.uk/en/Publicationsandstatistics/Publications/Publications PolicyAndGuidance/DH_4137040 (accessed 30 September 2007).

Department of Health (2007) Putting People First: A Shared Vision and Commitment to the Transformation of Adult Social Care, available online at www.dh.gov.uk/en/Publicationsandstatistics/PublicationsPolicyand Guidance/ DH 081118 (accessed 7 February 2008).

Doel, M., Carroll, C., Chambers, E., Cooke, J., Hollows, A., Laurie, L., Maskrey, L. and Nancarrow, S. (2007) Developing measures for effective service users and career participation, Social Care Institute for Excellence, Position paper 9, available online at www.scie.org.uk/publications/positionpapers/pp09.asp (accessed 30 September 2007).

Doucet, A. and Mauthner, N. (2003) 'Reflexive Accounts and Accounts of Reflexitity in Qualitative Data Analysis', Sociology, 37 (3), pp.413431.

Evans, R. and Banton, M. (2001) Involving Black Disabled People in Shaping Services, Joseph Rowntree Foundation, Findings D61, available online at www.jrf.org.uk/knowledge/findings/socialcare/pdf/D61.pdf (accessed 7 March 2007). 
Fountain, J. and Howes, S. (2002) Home and Dry? Homelessness and Substance use in London, unpublished, London, Crisis.

Grange, R. (1998) 'Establishing causality in evaluations of comprehensive community initiatives', in Fullbright-Anderson, K., Kubisch, A. and Connell, J. (eds), New Approaches to Evaluating Community Initiatives: Concepts, Methods, and Contexts, Volume 2, Washington, Aspen Institute.

Harris, J. and Bamford, C. (2001) The uphill struggle: services for deaf and hard of hearing people - issues of equality participation and access', Disability and Society, 16 (7), pp. 969-979.

Hart R. (1997) Children's Participation: The Theory and Practice of Involving Young Citizens in Community Development and Environmental Care, Earthscan Publications and UNICEF.

Health and Social Care Advisory Service (2005) Making a Real Difference; Strengthening Service User and Carer Involvement in National Institute for Mental Health in England, final report, unpublished.

Hubbard, G., Cook, A., Tester, S. and Downs, M. (2002) 'Beyond words: older people with dementia using and interpreting non-verbal behaviour', Journal of Aging Studies, 16 (2), pp.155- 167.

Hussain, Y., Atkin, K. and Ahmad, W. (2002) South Asian Disabled Young People and their Families, Bristol, Policy Press.

Law, J., Bunning,K., Byng, S., Farrelly, S. and Heyman, B. (2005) 'Making sense in primary care: levelling the playing field for people 
with communication difficulties', Disability \& Society, 20 (2), pp.169184.

Leonard Cheshire (2005) Service User Involvement in Leonard Cheshire, Trowbridge, Leonard Cheshire Foundation.

Moriarty, J., Rapaport, P., Manthorpe, J., Cornes, M., Martineau, S., Beresford, P., Branfield, F., Forrest, V., Butt, J. and Iliffe, S. (2006) The Participation of Adult Service Users, Including Older People, in Developing Social Care, Stakeholder Participation Guide 11, Social Care Institute for Excellence, available online at www.scie.org.uk/publication/ practiceguides/practiceguide1l/ind ex.asp (accessed 30 September 2007).

Parmar, A. and Sampson, A. (2007) 'Evaluating domestic violence initiatives', British Journal of Criminology, 47 (4), pp. 671- 691.

Parr, S. (2004) Living with Communication Impairment, Communications Forum, available online at www.communicationsforum.org.uk/Docs/LivingWith/Communicationl mpairments.pdf (accessed 22 September 2006).

Parr, S., Byng, S., Barnes, C. and Mercer, G. (2004) Social Exclusion of People with Marked Communication Impairment following Stroke, Joseph Rowntree Foundation Findings 814, available online at www.jrf.org.uk/knowledge/findings/socialcare/pdf/814.pdf (accessed 7 March 2007).

Pawson, R. and Tilley, N. (1997) Realistic Evaluation, London, Sage. 
Popper, K. (1968) The Logic of Scientific Discovery, $2^{\text {nd }}$ edition, London, Hutchinson.

Popper, K. (1969) Conjectures and Refutations: The Growth of Scientific Knowledge, $3^{\text {rd }}$ edition, London, Routledge.

Robson, P., Sampson, A., Dime, N., Hernandez, L. and Litherland, R. (2008) Seldom-heard: Developing inclusive participation in social care, Position paper 10, London, Social Care Institute for Excellence.

Sayer, A. (1992) Method in Social Science: A Realist Approach, $2^{\text {nd }}$ edition, London, Routledge.

Singh B (2005) Making Change Happen for Black and Minority Ethnic and Disabled People, Joseph Rowntree Foundation Findings, November, available online at www.jrf.org.uk/Knowledge/ findings/ socialcare/ 0495.asp (accessed 22 September 2006).

Vernon, A. (2002) Users' Views of Community Care for Asian Disabled People, Joseph Rowntree Foundation, Findings 752, available online at www.jrf.org.uk/knowledge/ findings/ socialcare/752.asp (accessed 22 September 2006).

Warburton, D. (2006) Evaluation of Your Health, Your Care, Your Say, Final Report, London, Department of Health, available online at www.dh.gov.uk/en/Publicationsandstatistics/Publications/Publications PolicyAndGuidance/DH_4138622 (accessed 7 March 2006). 
Weiss, C. (1997a) 'How can theory-based evaluation make greater headway?', Evaluation Review, 21, pp.501- 24.

Weiss, C. (1997b) 'Theory- based evaluation: past, present and future', New Directions for Evaluation, 76, pp 41- 55.

Wright, P., Turner, C., Clay, D. and Mills, H. (2006) The Participation of Children and Young People in Developing Social Care, Practice Guide 06, Social Care Institute for Excellence, available online at www.scie.org.uk/publications/practiceguides/practiceguide06/files/p g06.pdf (accessed 7 March 2006).

Yu W. K. (2000) Meeting the Needs of Chinese Older People, Joseph Rowntree Findings 920, available online at www.jrf.org.uk/knowledge/findings/ socialcare/920.asp (accessed 22 September 2006).

\section{Acknowledgements}

We would like to thanks the Social Care Institute for Excellence for funding this research, Nnamdi Dime and Rachel Litherland two of the project's researchers for their excellent fieldwork, Robin Mutter for his comments on an earlier draft of the paper, and two anonymous reviewers for their constructive comments. 
